\title{
Is Transarterial Chemoembolization Only Treatment Option in Patients with Intermediate Stage of Hepatocellular Carcinoma?: in Perspectives of Surgery
}

\author{
Ji Young Lim', Minjong Lee ${ }^{2}$, Tae Hun Kim² \\ 'Department of Health Promotion Center, Eunpyeong St. Mary's Hospital, College of Medicine, The Catholic University of Korea, Seoul; \\ ${ }^{2}$ Department of Internal Medicine, Ewha Womans University College of Medicine, Seoul, Korea
}

Received Jul. 4, 2020

Revised Jul. 30, 2020

Accepted Jul. 31,2020
In the Barcelona Clinic Liver Cancer staging system, intermediate stage hepatocellular carcinoma (HCC) is defined as large multinodular tumors without vascular invasion or extrahepatic spread in an asymptomatic patient with good performance status. Intermediate stage HCC includes various subgroups and it is characterized by extensive heterogeneity. Current guidelines recommend transarterial chemoembolization (TACE) as the standard treatment modality for patients with intermediate stage HCC. Although TACE provides improved survival benefits compared with supportive care for patients with intermediate stage HCC, all of them are not good candidates for TACE. TACE refractoriness is another obstacle to effective treatment of patients with intermediate stage HCC. Given that many studies recently reported improved survival in patients treated with hepatic resection over TACE, we reviewed the survival outcomes of TACE and hepatic resection as a treatment strategy of intermediate stage HCC. (J Liver Cancer 2020;20:113-119)

Keywords: Surgery; Transarterial chemoembolization; Hepatocellular carcinoma

\section{INTRODUCTION}

Hepatocellular carcinoma (HCC) is the fourth leading cause of cancer-related deaths globally. ${ }^{1}$ Despite advances in treatment, the overall prognosis of HCC remains poor compared to other cancers. ${ }^{1}$ The management of HCC is complicated in that not only the tumor burden itself, but also the liver function should be considered. The Barcelona Clinic Liver Cancer (BCLC) staging system is widely used for the treatment and

\section{Corresponding author: Minjong Lee}

Department of Internal Medicine, Ewha Womans University Seoul Hospital, Ewha Womans University College of Medicine, 260 Gonghangdaero, Gangseo-gu, Seoul 07804, Korea

Tel. +82-2-6986-1760, Fax. +82-2-6986-1761

E-mail; minjonglee2@naver.com

https://orcid.org/0000-0002-3159-5444 prognosis of HCC. ${ }^{2}$ The BCLC system takes account of liver function, tumor burden, as well as the performance status of the patient classified as HCC into 5 stages $(0, \mathrm{~A}-\mathrm{D}) .^{3}$ In the BCLC staging system, intermediate stage is referred to multinodular lesions, well-preserved liver function (Child-Pugh class A or B), and good performance status. ${ }^{3}$ As per the BCLC staging system, the recommended treatment for patients with intermediate stage HCC, i.e., BCLC B, is transarterial chemoembolization (TACE). However, TACE may not be suitable for all patients with intermediate stage HCC. In these cases, other forms of treatment should be considered, such as surgery. Recent studies have demonstrated that hepatic resection provides a survival benefit over TACE in intermediate stage HCC., ${ }^{4,5}$ This review evaluates the role of TACE and hepatic resection in the treatment of intermediate stage HCC. 


\section{TRANSARTERIAL CHEMOEMBOLIZATION}

According to the current guidelines, TACE is the standard care for patients with intermediate stage HCC. ${ }^{3}$ The survival benefit of TACE has been noted in several randomized controlled studies. As the first randomized controlled study showing the efficacy of TACE, Llovet et al. ${ }^{6}$ reported that patients with unresectable HCC who were not suitable for $\mathrm{cu}$ rative treatment showed a longer mean survival time (28.7 months) in the TACE group compared to the group receiving conservative management (17.9 months). Additionally, a randomized controlled study in Hong Kong demonstrated significantly better 1 - and 3-year survival rates in the TACE group (57\% and $26 \%$, respectively) than those in control group (32\% and 3\%, respectively). ${ }^{7}$ A meta-analysis has suggested that patients with unresectable HCC demonstrate prolonged survival when treated with TACE in comparison to conservative management. ${ }^{8}$ It analyzed 7 trials (total of 545 patients) to compare the survival benefits of TACE and conservative treatment in unresectable HCC. TACE group showed significantly better 2-year survival than the control group (odds ratio $0.53, P=0.017$ ).

Recently, drug-eluting bead TACE (DEB-TACE) has been introduced as a novel regimen to conventional TACE (cTACE). It involves polymeric microspheres that are loaded with anti-neoplastic drugs, and after delivery to the tumor vasculature, drugs are released slowly over time allowing lower systemic toxicity and the higher drug concentrations in the target tumor. ${ }^{9}$ However, the superior clinical efficacy of DEB-TACE over cTACE is still debatable due to the lack of evidence. In randomized controlled trials conducted with the Western population, DEB-TACE did not show superiority as compared to cTACE in terms of 2-year survival, $56.8 \%$ vs. $55.4 \%$, respectively $(P=0.95) .{ }^{10}$ Similarly, a retrospective study reported comparable overall survival after cTACE and DEB-TACE, 13.6 months vs. 12.3 months, respectively. ${ }^{11}$ In a recent randomized controlled trial comparing DEB-TACE and cTACE, both were found to be equally effective and safe, with the only advantage of DEB-TACE being less post-procedural abdominal pain. ${ }^{10}$

\section{HETEROGENEITY OF INTERMEDIATE STAGE HCC}

In most of the previous studies reporting the efficacy of TACE, it was indicated for patients with asymptomatic, multinodular HCC without vascular or extrahepatic invasion, and preserved liver function; however, it is unclear whether all patients with intermediate stage HCC should be treated with TACE because of extensive heterogeneity in tumor burden and liver function. ${ }^{12,13}$ The necessity of subclassification of intermediate stage was recognized because of different prognosis even in the same 'intermediate stage'. Tumor burden and residual liver function were classified in more detail according to prognosis of these patients.

Bolondi et al. ${ }^{13}$ suggested to divide the intermediate stage into four subgroups (B1-B4) based on tumor burden and liver function, and proposed first and alternative treatment options for each subgroup (Table 1). In a retrospective study to validate the Bolondi subclassification, the median overall survival in each

Table 1. Bolondi's subclassification for intermediate stage of HCC

\begin{tabular}{lcccc}
\hline Subclassification & B1 & B2 & B3 & B4 \\
\hline Child-Pugh score & $5-7$ & $5-6$ & 7 & $8-9$ \\
Beyond Milan within up-to-7 criteria & In & Out & Out & Any \\
ECOG-PS & 0 & 0 & 0 & No \\
Portal vein thrombosis & No & No & $(-)$ & No \\
First treatment & TACE & TACE or TARE & Research trials supportive care \\
Alternative option & Liver transplantation or & Sorafenib & TACE+sorafenib & Liver transplantation \\
\end{tabular}

ECOG-PS, Eastern Cooperative Oncology Group tumor-related performance status; TACE, transarterial chemoembolization; TARE, transarterial radioembolization. 
group was different according to B1-B4 subgroups: 31.9, 26.9, 13.5, and 10.9 months, respectively. ${ }^{14}$ Ciria et al. ${ }^{15}$ also reported different survival outcomes in subgroups (5-year survival rate, $62.9 \%, 28.1 \%$ and $15.4 \%$, respectively, for B1, B2, and B3-4 subgroups, $P=0.004)$. In addition, Kinki criteria was also developed as a modification of the Bolondi criteria, which classified the intermediate stage HCC into three subgroups based on the Child-Pugh score, beyond Milan, and up-to-7 criteria (Table 2). ${ }^{16}$ Arizumi et al. ${ }^{17}$ demonstrated validation of Kinki criteria for patients with intermediate stage HCC in the Asian population. In this study, each subgroup showed significantly different median overall survival: 4.3 years, 2.9 years, and 1.1 years for B1, B2, and B3, respectively $(P<0.001)$. Another study to validate Kinki criteria with a retrospective design showed similar results of different median survival rates as 3.9 years, 2.5 years, and 1.1 years for B1, B2, and B3, respectively $(P<0.001) .^{17}$

\section{TACE REFRACTORINESS}

Repeated cycles of TACE can increase the efficacy of treatment, but may also increase the incidence of complications. In some patients, HCC may not respond well to TACE. Thus, when TACE is repeated in a particular patient, it is necessary to consider whether to continue or stop TACE, and switch to alternative treatment; TACE refractoriness. ${ }^{18}$ In general, the discontinuation of TACE is recommended if the tumor is non-responsive to two consecutive TACE treatment or if complications occur. ${ }^{19,20}$ Recently, in Asia-Pacific Primary Liver Cancer Expert Consensus Statements, ${ }^{21}$ it was emphasized that TACE should be discontinued in patients who showed TACE failure/refractoriness in order to preserve residual liver function. Targeted therapy such as sorafenib is the recommended first-line treatment for TACE-unsuitable patients. In a retrospective study reporting this issue, among 249 patients with intermediate stage of HCC who underwent first TACE, 122 showed TACE-refractoriness. The median overall survival was significantly longer in the sorafenib conversion group compared to the TACE-repeated group (25.4 months vs. 11.5 months, respectively, $P=0.003){ }^{22}$ A retrospective cohort study reported similar results. When 56 patients with intermediate stage HCC who were diagnosed to be refractory to TACE were divided into TACE-repeated group (24 patients) and switching to sorafenib group (32 patients), the median overall survival was significantly different: 13.6 months for TACE-repeated group, and 24.7 months for sorafenib switching group $(P=0.002){ }^{23}$

\section{SURGICAL RESECTION, AN ALTERNATIVE TO TACE IN THE INTERMEDIATE STAGE?}

Surgical treatment of HCC should be determined based on sufficient consideration of tumor burden, liver functional re-

Table 2. Kinki criteria (modified Bolondi's subclassification)

\begin{tabular}{|c|c|c|c|c|}
\hline Subclassification & B1 & B2 & B & 3 \\
\hline Child-Pugh score & $5-7$ & $5-7$ & 8 & 9 \\
\hline \multirow[t]{2}{*}{ Beyond Milan within up-to-7 criteria } & \multirow[t]{2}{*}{$\ln$} & \multirow[t]{2}{*}{ Out } & \multicolumn{2}{|c|}{ Any } \\
\hline & & & $\ln (\mathrm{B} 3 \mathrm{a})$ & Out (B3b) \\
\hline Concept of treatment & Curative & $\begin{array}{c}\text { Palliative } \\
\text { Non-curative }\end{array}$ & $\begin{array}{l}\text { Curative intent if } \\
\text { within up-to-7 }\end{array}$ & $\begin{array}{c}\text { Palliative } \\
\text { No treatment }\end{array}$ \\
\hline Treatment option & Resection, ablation, c-TACE & $\begin{array}{c}\text { DEB-TACE }{ }^{*}, \text { HAIC }^{\dagger} \\
\text { sorafenib }\end{array}$ & $\begin{array}{l}\text { Liver transplantation, } \\
\text { ablation, c-TACE }\end{array}$ & $\begin{array}{c}\text { HAIC, }^{\dagger} \\
\text { DEB-TACE }\end{array}$ \\
\hline Alternative & $\begin{array}{c}\text { DEB-TACE } \\
\text { (if large HCC, Child-Pugh score 7) } \\
\text { B-TACE }\end{array}$ & c-TACE & $\begin{array}{c}\text { DEB-TACE, } \\
\text { B-TACE }^{\S}, \text { HAIC }^{\dagger}\end{array}$ & Best supportive care \\
\hline
\end{tabular}

C-TACE, conventional transarterial chemoembolization; DEB-TACE, drug-eluting beads transarterial chemoembolization; HAIC, hepatic arterial infusion chemotherapy; HCC, hepatocellular carcinoma; B-TACE, balloon-occluded TACE.

*DEB-TACE is recommended for tumor $>6 \mathrm{~cm}$; ${ }^{+} \mathrm{HAIC}$ is recommended for multiple tumors $>6$; ${ }^{\ddagger}$ Sorafenib is recommended for Child-Pugh socre $5-6 ;{ }^{\circledR} \mathrm{B}-\mathrm{TACE}$ is recommended for fewer tumors. 
serve, and shortage of liver graft. ${ }^{24}$ Patients with chronic liver disease who have poor liver function have less range of resection than those with normal liver function. ${ }^{25}$ According to the BCLC staging system, surgical resection of HCC is limited to those in the early stage of HCC. ${ }^{26,27}$ It recommends surgical resection only when patients had a single nodule of HCC or multiple tumors $\leq 3$ in number with $<3 \mathrm{~cm}$ of tumor diameter with good liver function. ${ }^{26,27}$ However, BCLC staging classification is based on a study that is more than 20 years old and leads to a conclusion from the analysis of a cohort of 77 early HCC patients and 102 intermediate or advanced HCC patients. ${ }^{28}$

Recent studies suggested that the indication of surgery for HCC treatment could be expanding to more advanced stages due to the development of surgical techniques and perioperative management. ${ }^{29}$ Many studies have reported survival benefits of surgery for patients with HCC, particularly intermediate stage (summarized in Table 3). ${ }^{4,1530-35}$ In a randomized controlled study for the Asian population, 173 HCC patients beyond Milan criteria were randomly assigned to surgery or TACE groups. It was reported that surgical resection demonstrated superiority over TACE in terms of overall survival (1-year and 3-year overall survival, $76.1 \%$ and 51.5\% in the surgical group, $51.8 \%$ and $18.1 \%$ in the TACE group, respectively, $P<0.001){ }^{4}$ The global study using a longitudinal cohort, categorized patients into four groups depending on whether or not they were an "ideal candidate" for resection, and whether or not they underwent resection. Of the 8,656 enrolled patients, 1,624 who had undergone hepatic resection were non-ideal candidates as per the current guidelines. There was a survival benefit when non-ideal patients underwent surgery rather than TACE (hazard ratio for survival $1.26, P<0.001) .{ }^{5}$ Although it may be prudent to suggest hepatic resection to patients who do not meet international criteria, it is noteworthy that resection of non-ideal candidate yielded better survival benefit compared to other treatments. $^{36}$

Several recent studies have shown that surgery in patients with intermediate stage HCC is as good as an early stage in terms of survival benefit. ${ }^{37,38}$ In a retrospective study con-

Table 3. Comparison of hepatic resection versus TACE in HCC patients with intermediate stage

\begin{tabular}{|c|c|c|c|c|c|c|c|c|c|}
\hline Year & Study design & $\begin{array}{l}\text { Treatment } \\
\text { group }\end{array}$ & $\begin{array}{l}\text { Patients } \\
\text { number }\end{array}$ & Tumor burden & $\begin{array}{l}\text { Child-Pugh } \\
\text { A/B (n) }\end{array}$ & $\begin{array}{l}\text { Median } \\
\text { OS } \\
\text { (months) }\end{array}$ & $\begin{array}{l}\text { 3-year } \\
\text { OS (\%) }\end{array}$ & $\begin{array}{l}5 \text {-year } \\
\text { OS (\%) }\end{array}$ & $P$-value ${ }^{*}$ \\
\hline 2014 & $\begin{array}{l}\text { Randomized } \\
\text { controlled } \\
\text { trial }\end{array}$ & $\begin{array}{l}\text { Surgery } \\
\text { TACE }\end{array}$ & $\begin{array}{l}88 \\
85\end{array}$ & $\begin{array}{l}\text { Resectable } \\
\text { outside Milan criteria } \\
\text { (no vascular invasion and } \\
\quad \text { extrahepatic metastasis) }\end{array}$ & $\begin{array}{l}87 / 1 \\
80 / 5\end{array}$ & 41 & $\begin{array}{l}51.5 \\
18.1\end{array}$ & $\begin{array}{l}\text { NR } \\
N R\end{array}$ & $<0.001$ \\
\hline 2011 & Prospective & $\begin{array}{l}\text { Surgery } \\
\text { TACE }\end{array}$ & $\begin{array}{l}85 \\
83\end{array}$ & $\begin{array}{l}\text { Intermediate stage and } \\
\text { solitary tumor } \geq 5 \mathrm{~cm}\end{array}$ & $\begin{array}{l}81 / 4 \\
82 / 1\end{array}$ & $\begin{array}{l}22.5 \\
19.5\end{array}$ & $\begin{array}{l}35.3 \\
26.0\end{array}$ & $\begin{array}{l}23.9 \\
18.9\end{array}$ & 0.26 \\
\hline 2017 & Retrospective & $\begin{array}{l}\text { Surgery } \\
\text { TACE }\end{array}$ & $\begin{array}{l}132 \\
132\end{array}$ & Intermediate stage & $\begin{array}{l}132 / 0 \\
132 / 0\end{array}$ & $\begin{array}{l}64 \\
41\end{array}$ & $\begin{array}{l}63.4 \\
53.0\end{array}$ & $\begin{array}{l}53.1 \\
34.1\end{array}$ & 0.01 \\
\hline 2016 & Retrospective & $\begin{array}{l}\text { Surgery } \\
\text { TACE }\end{array}$ & $\begin{array}{r}52 \\
225\end{array}$ & Intermediate stage & $\begin{array}{c}51 / 1 \\
187 / 38\end{array}$ & $\begin{array}{l}61 \\
30\end{array}$ & $\begin{array}{l}65.0 \\
39.2\end{array}$ & $\begin{array}{l}51.8 \\
27.9\end{array}$ & 0.02 \\
\hline 2016 & Retrospective & $\begin{array}{l}\text { Surgery } \\
\text { TACE }\end{array}$ & $\begin{array}{l}274 \\
169\end{array}$ & Intermediate stage & $\begin{array}{l}274 / 0 \\
169 / 0\end{array}$ & $\begin{array}{l}31.9 \\
14.3\end{array}$ & $\begin{array}{l}46 \\
15\end{array}$ & $\begin{array}{l}37 \\
12\end{array}$ & $<0.001$ \\
\hline 2015 & Retrospective & $\begin{array}{l}\text { Surgery } \\
\text { TACE }\end{array}$ & $\begin{array}{l}36 \\
44\end{array}$ & Intermediate stage & $\begin{array}{l}32 / 4 \\
29 / 15\end{array}$ & $\begin{array}{l}N R \\
N R\end{array}$ & $\begin{array}{l}52.8 \\
47.7\end{array}$ & $\begin{array}{l}44.4 \\
38.6\end{array}$ & 0.23 \\
\hline 2014 & Retrospective & $\begin{array}{c}\text { Surgery } \\
\text { TACE }\end{array}$ & $\begin{array}{r}433 \\
490 \\
\end{array}$ & Intermediate stage & $\begin{array}{l}328 / 105 \\
381 / 109 \\
\end{array}$ & $\begin{array}{l}24.8 \\
26.9 \\
\end{array}$ & $\begin{array}{l}71.1 \\
62.2 \\
\end{array}$ & $\begin{array}{l}61.2 \\
45.1 \\
\end{array}$ & $<0.001$ \\
\hline
\end{tabular}

TACE, transarterial chemoembolization; HCC, hepatocellular carcinoma; OS, overall survival; NR, not reported.

"Multivariate Cox regression models were used for $P$-value. 
ducted in Asia, HCC patients with intermediate stage showed comparable 5-year survival rates and median survival (50.5\% of 5-year survival, 60.4 months of median survival time in patients with intermediate stage HCC). ${ }^{38}$ A multi-institutional database enrolled 875 patients who underwent surgery, of which 380 had tumor burden of single $>5 \mathrm{~cm}$ or multinodular. The results showed that the overall survival rate was superior as compared to survival rates in patients treated with TACE in previous studies (1-year, 3-year, and 5-year overall survival, $74 \%, 50 \%$, and $39 \%$, respectively, $P<0.001) .{ }^{39}$ Furthermore, a prospective study comparing TACE and hepatic resection as initial treatment enrolled 168 patients with resectable, multiple nodules, and diameter of main tumor $5 \mathrm{~cm}$ or larger. Overall survival rates were $23.9 \%$ for the hepatic resection group and $18.9 \%$ for the TACE group although there was no significant difference of survival between the two groups because of small study numbers $(P=0.26){ }^{32}$

\section{CONCLUSIONS}

According to the current treatment guideline, TACE is the standard care for intermediate stage HCC. However, there are three major aspects that should be considered while indicating TACE in patients with intermediate stage HCC: 1) heterogeneity of intermediate stage, a wide range of tumor burden and liver function, 2) TACE refractoriness, and 3) good survival outcomes of surgical treatment in some HCC patients with intermediate stage. Expanding the indications for hepatic resection in patients with intermediate stage HCC still remains controversial, and most of the previous studies comparing survival benefit of resection and TACE were retrospective. However, surgical resection may provide survival benefits in patients with intermediate stage HCC who had good liver function and resectable HCCs, and particularly who were predicted to have a poor prognosis after TACE treatment such as TACE refractoriness. More evidence through a well-designed, randomized control study is required for expanding surgical criteria for intermediate stage HCC and identifying patients who have survival benefits when treated with resection over TACE.

\section{STATEMENT OF FINANCIAL SUPPORT}

This study was supported by a grant from Basic Science Research Program through the National Research Foundation of Korea (NRF) funded by the Ministry of Education (grant number: 2017R1D1A1B03031499), and a grant and supported by the National Research Foundation of Korea (NRF) grant funded by the Korea government (Ministry of Science and ICT) (grant number: 2020R1C1C1004112).

\section{Conflicts of Interest}

The authors declare no conflicts of interest relevant to this article.

\section{REFERENCES}

1. Bray F, Ferlay J, Soerjomataram I, Siegel RL, Torre LA, Jemal A. Global cancer statistics 2018: GLOBOCAN estimates of incidence and mortality worldwide for 36 cancers in 185 countries. CA Cancer J Clin 2018;68:394-424.

2. Lammer J, Malagari K, Vogl T, Pilleul F, Denys A, Watkinson A, et al. Prospective randomized study of doxorubicin-eluting-bead embolization in the treatment of hepatocellular carcinoma: results of the PRECISION V study. Cardiovasc Intervent Radiol 2010;33:41-52.

3. European Association for the Study of the Liver, EASL-EORTC. EASLEORTC clinical practice guidelines: management of hepatocellular carcinoma. J Hepatol 2012;56:908-943.

4. Yin L, Li H, Li AJ, Lau WY, Pan ZY, Lai EC, et al. Partial hepatectomy vs. transcatheter arterial chemoembolization for resectable multiple hepatocellular carcinoma beyond Milan Criteria: a RCT. J Hepatol 2014;61:82-88.

5. Roayaie S, Jibara G, Tabrizian P, Park JW, Yang J, Yan L, et al. The role of hepatic resection in the treatment of hepatocellular cancer. Hepatology 2015;62:440-451.

6. Llovet JM, Real MI, Montaña X, Planas R, Coll S, Aponte J, et al. Arterial embolisation or chemoembolisation versus symptomatic treatment in patients with unresectable hepatocellular carcinoma: a randomised controlled trial. Lancet 2002;359:1734-1739.

7. Lo CM, Ngan H, Tso WK, Liu CL, Lam CM, Poon RT, et al. Randomized controlled trial of transarterial lipiodol chemoembolization for unresectable hepatocellular carcinoma. Hepatology 2002;35:11641171.

8. Llovet JM, Bruix J. Systematic review of randomized trials for unresectable hepatocellular carcinoma: chemoembolization improves survival. Hepatology 2003;37:429-442.

9. Varela $M$, Real MI, Burrel M, Forner A, Sala M, Brunet $M$, et al. Chemoembolization of hepatocellular carcinoma with drug elut- 
ing beads: efficacy and doxorubicin pharmacokinetics. J Hepatol 2007:46:474-481.

10. Golfieri R, Giampalma E, Renzulli M, Cioni R, Bargellini I, Bartolozzi $C$, et al. Randomised controlled trial of doxorubicin-eluting beads vs conventional chemoembolisation for hepatocellular carcinoma. Br J Cancer 2014;111:255-264.

11. Kloeckner R, Weinmann A, Prinz F, Pinto dos Santos D, Ruckes C, Dueber $C$, et al. Conventional transarterial chemoembolization versus drug-eluting bead transarterial chemoembolization for the treatment of hepatocellular carcinoma. BMC Cancer 2015;15:465.

12. Roccarina D, Majumdar A, Thorburn D, Davidson BR, Tsochatzis E, Gurusamy KS. Management of people with intermediate-stage hepatocellular carcinoma: an attempted network meta-analysis. Cochrane Database Syst Rev 2017;3:CD011649.

13. Bolondi L, Burroughs A, Dufour JF, Galle PR, Mazzaferro V, Piscaglia $F$, et al. Heterogeneity of patients with intermediate (BCLC B) hepatocellular carcinoma: proposal for a subclassification to facilitate treatment decisions. Semin Liver Dis 2012;32:348-359.

14. Weinmann A, Koch S, Sprinzl M, Kloeckner R, Schulze-Bergkamen $H$, Düber $C$, et al. Survival analysis of proposed BCLC-B subgroups in hepatocellular carcinoma patients. Liver Int 2015;35:591-600.

15. Ciria R, López-Cillero P, Gallardo AB, Cabrera J, Pleguezuelo M, Ayllón $M D$, et al. Optimizing the management of patients with $B C L C$ stage-B hepatocellular carcinoma: modern surgical resection as a feasible alternative to transarterial chemoemolization. Eur J Surg Oncol 2015:41:1153-1161.

16. Kudo M, Arizumi T, Ueshima K, Sakurai T, Kitano M, Nishida N. Subclassification of BCLC B stage hepatocellular carcinoma and treatment strategies: proposal of modified Bolondi's subclassification (Kinki criteria). Dig Dis 2015;33:751-758.

17. Arizumi T, Ueshima K, Iwanishi M, Minami T, Chishina H, Kono M, et al. Validation of Kinki criteria, a modified substaging system, in patients with intermediate stage hepatocellular carcinoma. Dig Dis 2016;34:671-678

18. Kudo M, Okanoue T, Japan Society of Hepatology. Management of hepatocellular carcinoma in Japan: consensus-based clinical practice manual proposed by the Japan Society of Hepatology. Oncology 2007;72 Suppl 1:2-15.

19. Reig M, Darnell A, Forner A, Rimola J, Ayuso C, Bruix J. Systemic therapy for hepatocellular carcinoma: the issue of treatment stage migration and registration of progression using the BCLC-refined RECIST. Semin Liver Dis 2014;34:444-455.

20. Dufour JF, Bargellini I, De Maria N, De Simone P, Goulis I, Marinho RT. Intermediate hepatocellular carcinoma: current treatments and future perspectives. Ann Oncol 2013;24 Suppl 2:ii24-29.

21. Kudo M, Han KH, Ye SL, Zhou J, Huang YH, Lin SM, et al. A changing paradigm for the treatment of intermediate-stage hepatocellular carcinoma: Asia-Pacific Primary Liver Cancer Expert Consensus Statements. Liver Cancer 2020;9:245-260.

22. Ogasawara S, Chiba T, Ooka Y, Kanogawa N, Motoyama T, Suzuki
E, et al. Efficacy of sorafenib in intermediate-stage hepatocellular carcinoma patients refractory to transarterial chemoembolization. Oncology 2014;87:330-341.

23. Arizumi T, Ueshima K, Minami T, Kono M, Chishina H, Takita M, et al. Effectiveness of sorafenib in patients with transcatheter arterial chemoembolization (TACE) refractory and intermediate-stage hepatocellular carcinoma. Liver Cancer 2015;4:253-262.

24. Akamatsu N, Cillo U, Cucchetti A, Donadon M, Pinna AD, Torzilli G, et al. Surgery and hepatocellular carcinoma. Liver Cancer 2016;6:4450.

25. Torzilli G, Makuuchi M, Inoue K, Takayama T, Sakamoto Y, Sugawara $Y$, et al. No-mortality liver resection for hepatocellular carcinoma in cirrhotic and noncirrhotic patients: is there a way? A prospective analysis of our approach. Arch Surg 1999;134:984-992.

26. Forner A, Llovet JM, Bruix J. Hepatocellular carcinoma. Lancet 2012;379:1245-1255.

27. Bruix J, Sherman M, American Association for the Study of Liver Disease. Management of hepatocellular carcinoma: an update. Hepatology 2011;53:1020-1022.

28. Llovet JM, Brú C, Bruix J. Prognosis of hepatocellular carcinoma: the BCLC staging classification. Semin Liver Dis 1999;19:329-338.

29. Clavien PA, Petrowsky H, DeOliveira ML, Graf R. Strategies for safer liver surgery and partial liver transplantation. N Engl J Med 2007;356:1545-1559.

30. Zhao YN, Zhang YQ, Ye JZ, Liu X, Yang HZ, Cong FY, et al. Hepatic resection versus transarterial chemoembolization for patients with Barcelona Clinic Liver Cancer intermediate stage Child-Pugh A hepatocellular carcinoma. Exp Ther Med 2016;12:3813-3819.

31. Tada T, Kumada T, Toyoda H, Tsuji K, Hiraoka A, Itobayashi E, et al. Role of hepatic resection in patients with intermediate-stage hepatocellular carcinoma: a multicenter study from Japan. Cancer Sci 2017;108:1414-1420.

32. Luo J, Peng ZW, Guo RP, Zhang YQ, Li JQ, Chen MS, et al. Hepatic resection versus transarterial lipiodol chemoembolization as the initial treatment for large, multiple, and resectable hepatocellular carcinomas: a prospective nonrandomized analysis. Radiology 2011;259:286-295.

33. Kim JY, Sinn DH, Gwak GY, Choi GS, Saleh AM, Joh JW, et al. Transarterial chemoembolization versus resection for intermediate-stage (BCLC B) hepatocellular carcinoma. Clin Mol Hepatol 2016;22:250258.

34. Jianyong L, Lunan Y, Wentao W, Yong Z, Bo L, Tianfu W, et al. Barcelona clinic liver cancer stage $B$ hepatocellular carcinoma: transarterial chemoembolization or hepatic resection? Medicine (Baltimore) 2014;93:e180.

35. Hyun MH, Lee YS, Kim JH, Lee CU, Jung YK, Seo YS, et al. Hepatic resection compared to chemoembolization in intermediate-to advanced-stage hepatocellular carcinoma: a meta-analysis of highquality studies. Hepatology 2018;68:977-993.

36. Cucchetti A, Djulbegovic B, Tsalatsanis A, Vitale A, Hozo I, Piscaglia 
$F$, et al. When to perform hepatic resection for intermediate-stage hepatocellular carcinoma. Hepatology 2015;61:905-914.

37. Wei $S$, Hao X, Zhan D, Xiong M, Li K, Chen $X$, et al. Are surgical indications of Barcelona Clinic Liver Cancer staging classification justified? J Huazhong Univ Sci Technolog Med Sci 2011;31:637.

38. Wang JH, Changchien CS, Hu TH, Lee CM, Kee KM, Lin CY, et al. The efficacy of treatment schedules according to Barcelona Clinic
Liver Cancer staging for hepatocellular carcinoma-Survival analysis of 3892 patients. Eur J Cancer 2008:44:1000-1006.

39. Ng KK, Vauthey JN, Pawlik TM, Lauwers GY, Regimbeau JM, Belghiti J, et al. Is hepatic resection for large or multinodular hepatocellular carcinoma justified? Results from a multi-institutional database. Ann Surg Oncol 2005;12:364-373. 